\title{
Hypoxia induces CD133 expression in human lung cancer cells by up-regulation of OCT3/4 and SOX2
}

\author{
HAJIME IIDA $^{1,2}$, MITSUHIRO SUZUKI ${ }^{1}$, RYO GOITSUKA $^{2}$ and HIKARU UENO ${ }^{1}$ \\ ${ }^{1}$ Department of Biochemistry, University of Occupational and Environmental Health; ${ }^{2}$ Division of Development \\ and Aging, Research Institute for Biological Sciences, Tokyo University of Science, Japan
}

Received May 5, 2011; Accepted June 14, 2011

DOI: 10.3892/ijo.2011.1207

\begin{abstract}
CD133 has been recognized as a specific cell surface marker for cancer stem cells in various tumors, although its biological functions and transcriptional regulation remain unclear. We found that the CD133 expression level was up-regulated in the lung cancer cell lines N417, H358, and A549, when these cell lines were cultured under hypoxic conditions. Among the five promoters (P1-P5) of human CD133 gene loci, P1 promoter was most strongly associated with hypoxia-induced promoter activity of $C D 133$ gene expression. The P1 promoter possesses several cis-regulatory elements, including RUNT, GATA, ETS, OCT, SRY, and CREB-binding sites. A series of deletion and base substitution mutants of the $\mathrm{P} 1$ promoter revealed that OCT- and SRY-binding sites are important for hypoxia-induced promoter activity. The chromatin immunoprecipitation assay further confirmed the direct binding of Octamer biding transcription factor 3/4 (OCT4) and/or SRY-box containing gene 2 (SOX2) to the P1 promoter region of $C D 133$ gene loci. In addition, the enhancement of both OCT4 and SOX2 expression by the $\alpha$ subunit of hypoxia-inducible factors (HIFl $\alpha$ and HIF2 $\alpha$ ) was required for hypoxia-induced CD133 expression. Knockdown of OCT4 or SOX2 expression in N417 cells with stabilized HIF1 $\alpha$ and/or HIF2 $\alpha$ abolished CD133P1 activity, while ectopic OCT4 or SOX2 expression triggers CD133P1 activity in the absence of HIF1 $\alpha$ or HIF2 $\alpha$. Thus, in the hypoxic conditions, OCT4 and SOX2, both of which are induced by HIF1 $\alpha /$ HIF2 $\alpha$ promote CD133 expression in the lung cancer cells via their direct interaction with the $\mathrm{P} 1$ promoter.
\end{abstract}

\section{Introduction}

Increasing evidence reveals that a single tumor consists of heterogenous cell populations in terms of their surface antigen expression as well as their functional activities to form colonies

Correspondence to: Dr Mitsuhiro Suzuki, Department of Biochemistry, University of Occupational and Environmental Health, 1-1 Iseigaoka, Yahatanishi, Kitakyushu, Fukuoka, Japan

E-mail: misuzuki@med.uoeh-u.ac.jp

Key words: cancer stem cell, CD133, gene expression, hypoxia, lung cancer in vitro. Two models have been proposed to explain the heterogeneity of cancer cells $(1,2)$. The stochastic (or clonal evolution) model suggests that every cancerous cell is homogeneous as a potential tumor initiator, but that heterogeneity arises from intrinsic and extrinsic factors by infrequent stochastic events. In contrast, the cancer stem cell (CSC) model proposes that heterogeneity occurs as a result of a hierarchal organization similar to embryonic or somatic stem cell-derived organogenesis. CSCs have recently been reported in leukemia (3), melanoma (4), glioma (5) and various types of carcinomas (6-8). The CSC model, however, does not answer the question whether cancers are originated from somatic stem cells. The cellular origins of these CSCs are barely known at present, however, several studies indicate that only few or extremely rare subpopulations of human cancer cells have tumorigenic potential when engrafted ex vivo into immunocompromised mice $(9,10)$.

The cell surface antigen CD133 (also known as AC133 or prominin-1) has been recognized as a marker for CSCs. CD133 has been identifed as a pentaspan transmembrane protein in neuroepithelial cells (11) and has been detected in human hematopoietic stem cells $(12,13)$ and several human solid malignancies, such as glioma (5), melanoma (14), osteosarcoma (15) hepatic cancer $(16,17)$, colon cancer $(10,18)$, ovarian cancer (19), and lung cancer (20). A previous report showed that the $\mathrm{CD} 33^{+}$subpopulation in glioma could generate tumors when transplanted into xenogenic immunocompromised mice, and such mice have higher resistance to radiation and chemotherapy (5). However, several groups have shown that both $\mathrm{CD}_{133^{+}}$and CD133- tumor populations have cancer stem cell-like characteristics, such as an ability to generate xenogenic tumor $(21,22)$. Human $C D 133$ has 5 promoters (P1, P2, P3, P4, and P5), and its first exon has 14 alternative spliced variants derived from their promoters, which regulate gene expression in various cell types in an interdependent manner (23).

Lung cancer remains the leading cause of cancer death, with small cell lung cancer (SCLC) showing a high degree of malignancy. CD133 has been reported to be expressed at very low levels $(<1 \%)$ in lung cancer stem cells $(24,25)$, but both $\mathrm{CD}_{133^{+}}$and $\mathrm{CD} 133^{-}$subpopulations possess tumor-initiating properties. A recent report showed that CD133 expression on tumor cells is controlled by a change in the microenvironment, known as CSC niche (26-28). Because it is widely accepted that the tumor microenvironment frequently contains hypoxic area with poor vascularization and that there is a potential link 
between the stem cell microenvironment and physiological oxygen concentration, we hypothesized that cancer cells can be a throw back to anaplatic cells like as embryonic stem cells by hypoxia. In the present study, we examined the possible association between hypoxia and cancer stem cell generation by analyzing transcriptional regulation of CD133 gene in the small cell lung cancer cell line.

\section{Materials and methods}

Cell cultures. All cells (N417, NCI-H157, NCI-H358, and A549) were cultured in RPMI-1640 medium containing L-glutamine (Gibco) and $10 \%$ fetal calf serum (Hyclone). For the standard normoxic condition of $20 \% \mathrm{O}_{2}$, all cells were maintained in a Forma $\mathrm{CO}_{2}$ incubator at $5 \% \mathrm{CO}_{2} / 95 \%$ air at $37^{\circ} \mathrm{C}$. For the hypoxic conditions of $5 \%$ or $0.1 \% \mathrm{O}_{2}$, cultures were maintained in an Anero Pack System (Mitsubishi Gas Chemical Company) using the MicroAero kit for $5 \% \mathrm{O}_{2}$ and the Anaero kit for $0.1 \%$ $\mathrm{O}_{2}$.

Plasmid construction. The reporter vectors in the promoter regulation studies were constructed by inserting the human CD133 promoter region amplified from genomic DNA into the pGL4.18 reporter vector (Promega). The human CD133 promoter region was obtained by genomic PCR using the primers as previously described (23). The insert was subcloned into the KpnI and HindIII sites of the pGL4.18 vector. All the cloned vectors were selected, and the inserted DNA was verified by sequencing.

Establishment of miR-expressed cell lines. HIF1amiR-, HIF2 $\alpha$ miR-, HIF1 $\alpha /$ HIF2 $\alpha$ miR-, OCT4miR-, SOX2miR-, and OCT4/SOX2miR-oligonucleotides were designed by using Block-it RNAi Designer (Invitrogen). Each miR-expressed cell lines was generated by transfection of N417 with pCDNA6.2miR vectors using Lipofectamin LTX (Invitrogen). Selections were performed in the culture medium with $1.0 \mu \mathrm{g} / \mathrm{ml}$ Blastcydin (Invitrogen).

Reverse transcriptase polymerase chain reaction (RT-PCR) and semi-quantitative real-time polymerase chain reaction ( $q P C R)$. Total RNA was prepared using the RNeasy kit (Qiagen), according to the manufacturer's protocol. First-strand cDNA was obtained by incubation of $1.0 \mu \mathrm{g}$ total RNA samples with oligo-dT ${ }_{20}, \mathrm{dNTPs}$, and reverse transcriptase (SuperScript III; Invitrogen), as previously described (29). RT-PCR reactions were performed by using $1 \mu \mathrm{l}$ of the RT-product, GoTaq polymerase (Promega), and the gene-specific primers. In all, 35 cycles of amplification were carried out under the following conditions for each cycle: denaturing at $94^{\circ} \mathrm{C}$ for $30 \mathrm{sec}$, annealing at $55^{\circ} \mathrm{C}$ for $30 \mathrm{sec}$, and extension at $72^{\circ} \mathrm{C}$ for $30 \mathrm{sec}$. $\beta$-actin was used as an internal control. qPCR reactions were performed using the ExTaq SYBR Green Supermix (Takara) and StepOnePlus (Applied Biosystems).

Luciferase reporter assay. Cell extracts for the luciferase assay were prepared as previously described (29). Vectors for the reporter gene (pGL4.18-CD133) and effector genes (pCMVFLAG-RUNX1, pCMV-FLAG-GATA1, pCMV-FLAG-ETS1, and pCMV-FLAG-EP300) were constructed as previously described (29). Expression vectors of both OCT4 and SOX2 were obtained from Flexi ORF clone (Promega) and were subcloned into pCMV-FLAG vector. The reporter and effecter vectors $(0.1 \mu \mathrm{g}$ each) were co-transfected into N417 cells cultured in 24-well plates. The luciferase assay was performed using $5 \mu \mathrm{l}$ of protein in the cell lysate and $100 \mu \mathrm{l}$ of Pikka-gene substrate (Nippon Gene), and activity was measured with a luminometer (Berthold, LB9501).

Flow cytometry analysis and fluorescence-activated cell sorting. The cells were triturated and filtered through a nylon screen ( $45 \mu \mathrm{m}$; Becton-Dickinson and Co.) to obtain a singlecell suspension. For isolation of $\mathrm{CD} 133^{-}$or $\mathrm{CD} 133^{+}$cells, N417 cells cultivated under normoxia or hypoxia were incubated with PE-conjugated monoclonal antibodies to CD133, and both CD133- and CD133+ populations were separately sorted by using FACSAria. Antibody against OCT3 and SOX2 was visualized using streptavidin APC-Cy7. Non-viable cells were excluded from sorts and analyses using the viability dye 7AAD $(1 \mu \mathrm{g} / \mathrm{ml})$.

Chromatin immunoprecipitation (ChIP) assay. ChIP assays were performed as previously described (29), with minor modifications. Antibodies against OCT4 (ab19857, abcam) and SOX2 (ab15830, abcam) were used for immunoprecipitation. The samples were subjected to 40 cycles of PCR amplification. The primers for detection of the OCT-binding site on CD133P1 were as follows: OCT-forward (human CD133P1 region at -501 to -482) 5'-GTTGTAACTCACAGAGCGG-3', OCT-reverse (CD133P1 at -347 to -326) 5'-ACAATCATTTGGATCCTT AGTG-3'. The primers for detection of the SRY-binding sites on CD133P1 were as follows: SRY-forward (CD133P1 at -347 to -327) 5'-CACTAAGGATCCAAATGATTG-3', SRY-reverse (CD133P1 at-209to-190)5'-TCCCTTACTTACTGGACAG-3' The primers for distal region on CD133P1 were as follows: distal-forward(CD133P1 at-1000 to-979) 5'-TCAATATGAGG ATTTGGATGGG-3', distal-reverse (CD133P1 at -821 to -799) 5'-TACCTTTTTCTTTTTACCCCAG-3'. The primers for exon 1 A region on CD133 were as follows: exon 1A-forward (CD133 at +16 to +34) 5'-ACCTGGCCATGCTCTCAGC-3', exon 1A-reverse (CD133 at+147 to-165)5'-GGCGGGAGGCA GGAGAAAG-3'.

\section{Results}

CD133 expression is induced in some lung cancer cell lines under hypoxic conditions. CD133 is a cell surface marker for CSCs, but CD133 expression in lung cancer cells has no significance (30). To verify whether CD133 can act as a cell marker for the detection of CSCs from lung cancers, we analyzed both transcriptional and translational levels of CD133 in four lung cancer cell lines by RT-PCR, FACS analysis, and immunohistochemistry. The transcriptional activities of NCI-N417, NCI-H358, and A549 cell lines were upregulated under hypoxic conditions (Fig. 1A). FACS analysis using the anti-AC133 (CD133/1) antibody revealed that N417, H358, and A549 cells cultivated under hypoxic conditions exhibit cellular heterogeneity for CD133 expression because the $\mathrm{CD}_{133^{+}}$subpopulation increased from $1.07,1.89$, and 1.27 to 12 , 8.12 , and $10.9 \%$, respectively. However, in the lung carcinoma cell line NCI-H157, almost no variation was observed between 

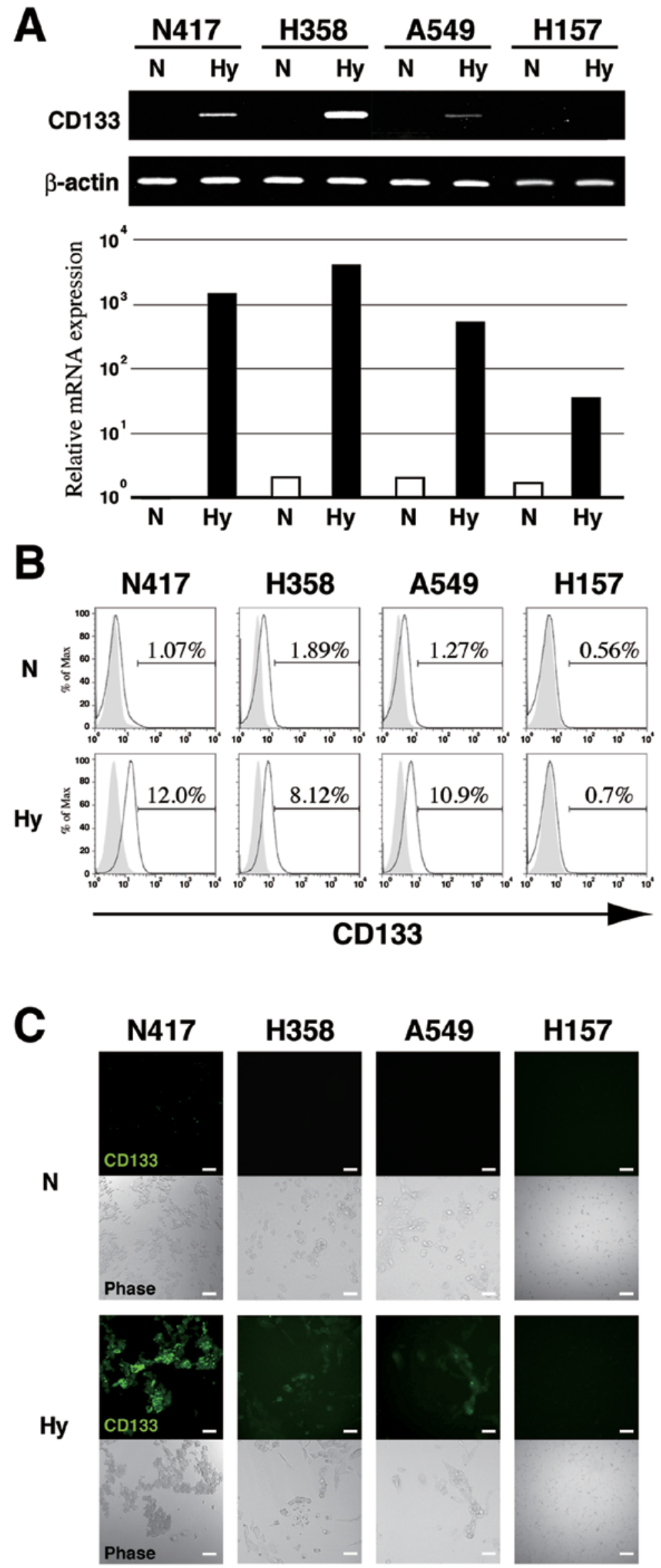

Figure 1. CD133 expression in human lung cancer cell lines as measured by: (A) conventional reverse transcriptase-PCR (upper column), and semi-quantitative real-time PCR (lower column) (B) FACS, and (C) immunofluorescence. Cells were cultured under normoxia $\left(\mathrm{N} ; 20 \% \mathrm{O}_{2}\right)$ or hypoxia $\left(\mathrm{Hy} ; 0.1 \% \mathrm{O}_{2}\right)$ for $12 \mathrm{~h}$. (A) Data were normalized to $\beta$-actin levels. (B) Numbers indicate the percentage of CD133 ${ }^{+}$cells in the total population, and the gray lines represent the isotype control antibody. (C) Each bar represents $100 \mu \mathrm{m}$. 
A

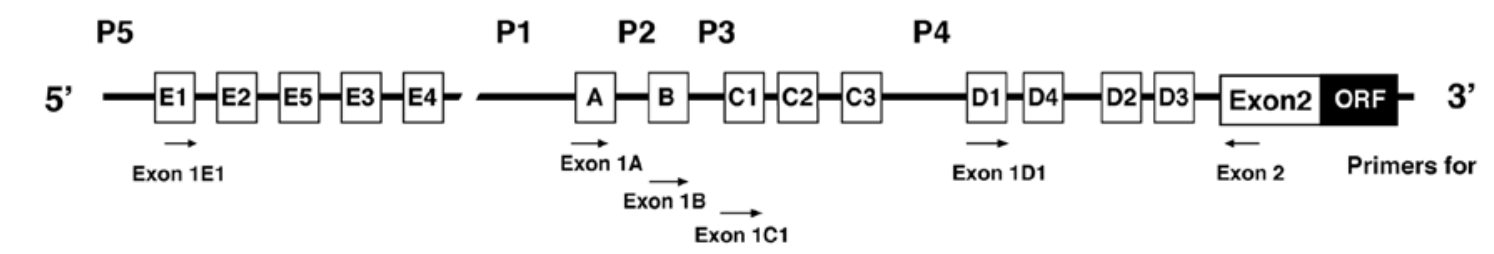

B

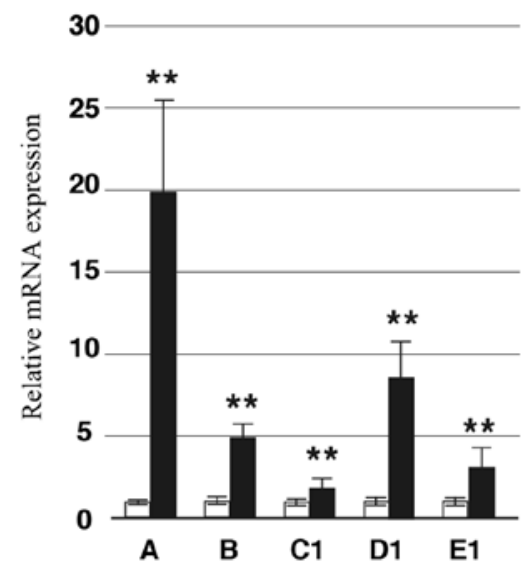

C

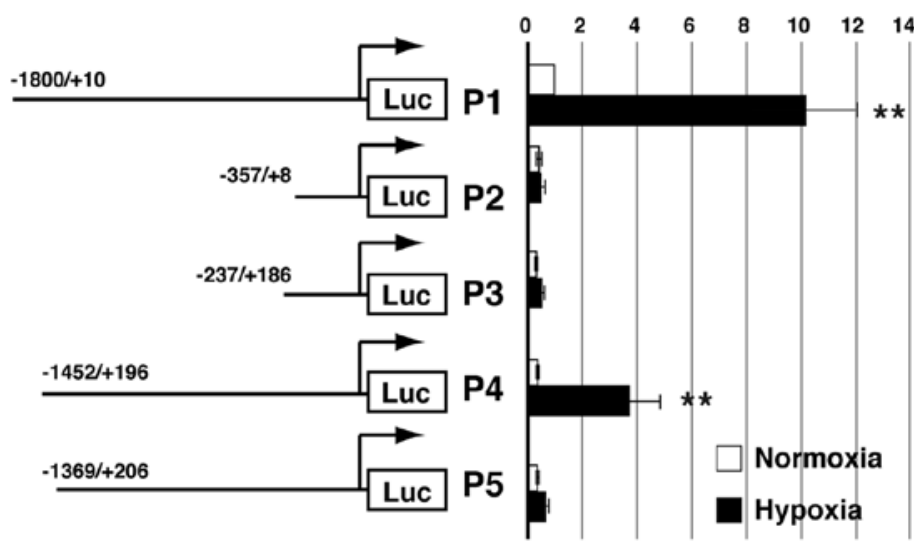

Figure 2. (A) Schematic representation of the positions of five CD133 promoters (P1-P5) and exon 1. (B) Semi-quantitative real-time PCR analysis was performed with primers specific for CD133 exons 1A, 1B, 1C1, 1D1, and 1E1. N417 cells were cultured under normoxia (N) or hypoxia (Hy) for 12 h. All data were normalized to $\beta$-actin levels. (C) Promoter activity of P1, P2, P3, P4, and P5 in N417. Left panel, schematic representation of luciferase reporter plasmid containing five CD133 promoters; right panel, luciferase activities of $\mathrm{N} 417$ cells transfected with the five indicated reporters. The levels of expression in hypoxia indicate significantly different from the levels in normoxia $\left(n=4,{ }^{* *} \mathrm{p}<0.01\right)$.

normoxic $\left(20 \% \mathrm{O}_{2}\right)$ and hypoxic $\left(0.1 \% \mathrm{O}_{2}\right)$ conditions (Fig. 1B). Immunohistochemical analysis also confirmed the presence of $\mathrm{CD}_{133}{ }^{+}$cells under hypoxia but not under normoxia, as positive signals for CD133 were observed strongly in N417 cells under hypoxia (Fig. 1C). Thus, lung cancer cells appear to retain the capacity to express a CSC marker, CD133, when these cells are exposed to hypoxic microenvironment, such as in tumor masses with poor vascularization.

The P1 promoter of CD133 gene is responsible for hypoxiainduced CD133 expression in lung cancer cells. The human CD133 gene transcribes at least 13 alternative splicing variants derived from 5 distinct promoters located upstream of different exon 1 (1A, 1B, 1C1, 1D1 and 1E), designated as P1, P2, P3, P4, and P5 (Fig. 2A) (13). Hypoxia-induced expression of CD133 in lung cancer cell lines prompted us to investigate the regulation of the $C D 133$ promoter activities in response to hypoxic conditions. To determine the exons and promoters involved in upregulation of CD133 in N417 cells under hypoxia, we assessed each transcript containing distinct exon 1 by semiquantitative PCR. Although all transcripts containing exons $1 \mathrm{~A}, 1 \mathrm{~B}, 1 \mathrm{C} 1,1 \mathrm{D} 1$, and $1 \mathrm{E}$ were elevated under hypoxic conditions than normoxic conditions, the transcript containing exon $1 \mathrm{~A}$ is the most up-regulated transcript under hypoxia among them, suggesting that $\mathrm{P} 1$ promoter located upstream of exon $1 \mathrm{~A}$ is the main hypoxia-responsive element of $C D 133$ gene expression in lung cancer cells (Fig. 2B). To confirm this preferential P1 promoter-driven CD133 gene transcription under hypoxia, each $C D 133$ gene promoter was fused to the luciferase reporter gene, and the promoter activity was examined in N417 cells by luciferase reporter assay. Consistent with the expression patterns of endogenous transcripts, $\mathrm{P} 1$ promoter activity was profoundly increased under hypoxia, whereas almost no increase was observed in P2, P4, and P5 promoter activities under hypoxia, although $\mathrm{P} 3$ promoter activity was modestly increased in response to hypoxia (Fig. 2C).

Hypoxia inducible factors are involved in the up-regulation of CD133 gene. The family of hypoxia-inducible factor (HIF) plays a critical role in mediating changes in gene expression in response to hypoxia, and their functional activities are positively regulated by stabilization of the $\alpha$ subunit of HIF (HIF $1 \alpha$, HIF $2 \alpha$, and HIF3 $\alpha$ ) under hypoxia (31). To verify whether stability of the $\alpha$ subunit of HIF influences $C D 133$ expression, the $\mathrm{P} 1$ promoter activity under the different hypoxia was examined. P1 activity $<20 \% \mathrm{O}_{2}$ was very low, whereas that of $<5$ and $0.1 \% \mathrm{O}_{2}$ increased by 6 - and 12 -fold, respectively (Fig. 3A). Furthermore, when we stabilized the $\alpha$ subunit of HIF under normoxia by using the proteasome inhibitor MG132 and the chemical inducer of HIF desferrioxamine (DFX), P1 promoter activity was elevated even in normoxia, which is dependent on the dose of HIF-stabilizing drugs (Fig. 3B), indicating that HIF1 $\alpha$ and/or HIF2 $\alpha$ are involved in hypoxia-induced up-regulation of $\mathrm{P} 1$ promoter activity of CD133 gene. Taken together, these findings indicate that the $\mathrm{P} 1$ promoter is mainly responsible for the hypoxia-induced CD133 expression in the lung cancer cell lines and also that hypoxia-associated transcription factor HIF1 $\alpha$ and/or HIF2 $\alpha$ 
A

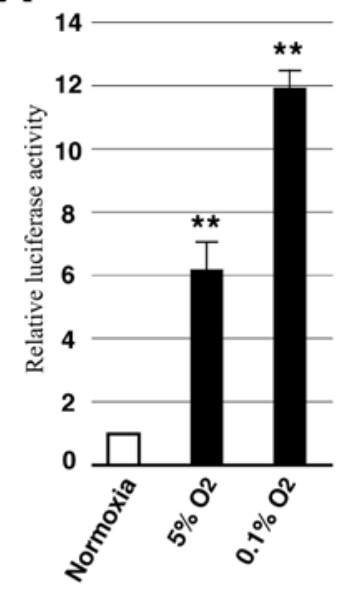

B

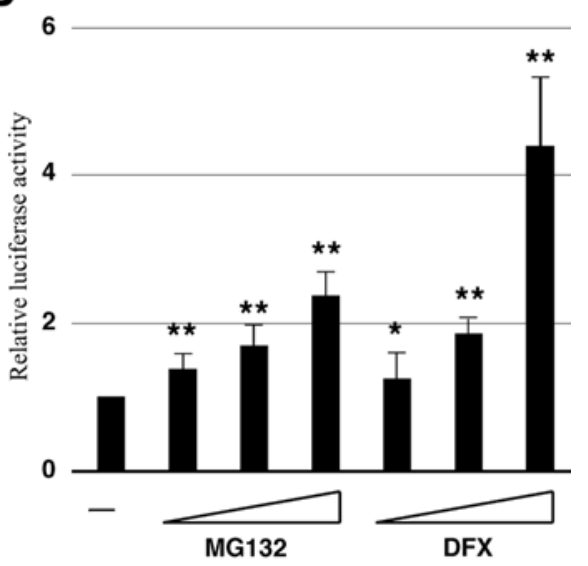

Figure 3. (A) P1 promoter activities of N417 cells cultured under normoxia or hypoxia for $12 \mathrm{~h}$. (B) Dose-dependent P1 promoter activities of cells treated with MG132 or desferrioxamine (DFX) to mimic hypoxia. N417 cells were treated with various concentrations of MG132 or DFX for $24 \mathrm{~h}$. All data are mean $\pm \mathrm{SD}$ of values from four independent experiments. Asterisk indicates significantly different from the normoxia $\left({ }^{*} \mathrm{p}<0.05\right.$ and ${ }^{* *} \mathrm{p}<0.01$ vs normoxia).

is responsible for up-regulation of $\mathrm{P} 1$ promoter activity under hypoxic conditions.

Oct3/4 and Sox2-binding sites of the P1 promoter in CD133 gene are involved in hypoxia-induced promoter activation. To understand the transcription factors responsible for the hypoxiainduced P1 promoter activation, we analyzed the cis-regulatory elements of P1 promoter sequences by searching putative transcription factor binding sites. Although we failed to find potential HIF-binding sites in the P1 promoter, P1 promoter $(-1891 /+400)$ from the transcription start site was revealed to contain several putative transcriptional binding sites, including four GATAs, one RUNT, three ETSs, one OCT, seven tandem repeats of SRYs, and one p300/CBP (Fig. 4A). To determine whether these cis-elements are involved in the $\mathrm{P} 1$ promoter activity under hypoxic conditions, we examined the changes in $\mathrm{P} 1$ promoter activity under normoxic conditions by overexpressing transcription factors potentially interacting with these sites. Overexpression of GATA1 and ETS1 slightly augmented P1 promoter activity, whereas RUNX1 and EP300 had no effect. Notably, overexpression of OCT4 and SOX2 induced significant P1 promoter activation even in normoxia (Fig. 3B). The region -368 to -361 of the $\mathrm{P} 1$ promoter has an OCT-binding site, and the region -322 to -285 has a seven-times repeated SRY-binding site. To confirm whether these regions participate in the hypoxia-induced P1 promoter activation, we generated a series of deletion and base substitution mutants of $\mathrm{P} 1$ promoter, and examined their responsiveness to hypoxia. We found that deletion to -360 or -267 decreased CD133P1 activation by one third, and base substitution mutants in the OCT-binding site and deletion in the SRY-binding site decreased the activation by half (Fig. 4C). These data suggest that both OCT4 and SOX2 are important trans-activators for $C D 133$ expression.

Inhibition of OCT4 and SOX2 expression abolishes CD133 activation under hypoxic conditions. A previous report indicated that HIF1 $\alpha$ and HIF2 $\alpha$ protein levels are stable under hypoxic conditions and that stability of these HIFs drives OCT4 and SOX2 expression (32). OCT4 and SOX2 are transcription factors that combine to form a heterodimerized complex and regulate other stemness genes such as NANOG and REX1 (33). CD133P1 may be upregulated by both HIFs and OCT4/SOX2. To confirm this possibility and the implication of OCT4/SOX2 regulation on $C D 133$ transcription, we used artificial miRNA that could be silenced by miRNAs of the $\alpha$ subunit of HIFs, OCT4, and SOX2. Compared with the control miR-expressing cells, OCT4-, SOX2-, OCT4/SOX2-, HIF1 $\alpha-$, HIF $2 \alpha-$, and HIF $1 \alpha / H I F 2 \alpha-m i R-e x p r e s s i n g ~ N 417$ cells were repressed by CD133P1-driven luciferase activity under hypoxic conditions (Fig. 5A). Similarly, enhancement of CD133 transcription by MG132 was reversed by OCT4- or SOX2-miR-expressing N417 cells (Fig. 5B). In addition, transient forced expression of OCT4 and SOX2 in the HIF-miR-expressing cell line still retained the ability to increase $C D 133$ transcription (Fig. 5C). These findings indicate that OCT4 and SOX2 can directly upregulate CD133 transcription without the involvement of HIFs.

$\mathrm{CD}_{133^{+}} \mathrm{N} 417$ cells express OCT4 and SOX2 under hypoxic conditions. To verify the involvement of OCT4 and SOX2 in CD133 transcription, we determined levels of OCT4 and SOX2 expressed by $\mathrm{CD}_{133^{-}}$and $\mathrm{CD} 133^{+}$cells by FACS analysis. On comparing the $\mathrm{CD}_{133^{+}}$and $\mathrm{CD} 133^{-}$population of N417, $\mathrm{H} 358$, $\mathrm{H} 460$, and $\mathrm{H} 157$ cells under hypoxic conditions, we found that both OCT4 and SOX2 were highly expressed by the CD133+ subpopulation of the cell lines examined. These results indicate that OCT4- and SOX2-binding motifs are required for CD133P1 activity (Fig. 6A).

Next, chromatin immunoprecipitation (ChIP) analysis was performed to assess whether OCT4 and SOX2 might interact with their own cis-elements (OCT and SRY) in the CD133 promoter region, distal promoter region and exon $1 \mathrm{~A}$ region. As shown in Fig. 6B, immunoprecipitates from N417 cells in hypoxia, but not in normoxia, which were formed by interaction with antibodies against both OCT4 and SOX2 enriched for the chromatin-containing OCT- and SRY-binding sites in the CD133 promoter region, were amplified by PCR. However, there is no amplification by PCR even in hypoxia for the chromatin-containing distal promoter region and exon $1 \mathrm{~A}$. These results strongly suggest that OCT4 and SOX2 are involved in the activity of the CD133 promoter region through direct interaction. 


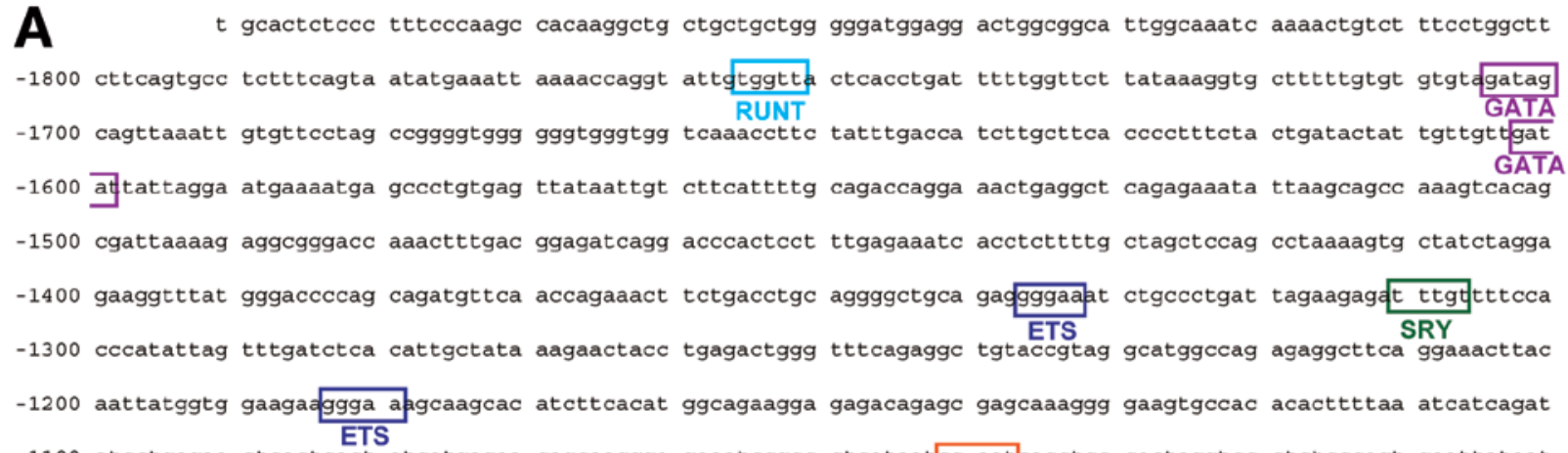
-1100 atcctgagaa ctcactcact atcatgagaa cagcaaggga gaaatccgcc ctcataatcc aatcacctcc cactaggtcc ctctcccagt gaattataat

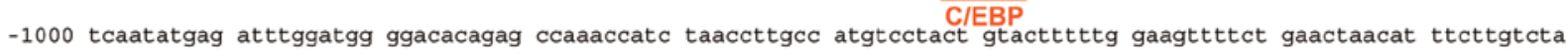
-900 gaaatataca cactcaagat caatctaact attaaaaaca aaaaatgctt attttccagt acctgtttta tgttagattc tggggtaaaa agaaaaaggt -800 actgacttaa tgttcctgtc tatcattcat ttgtagcttg tgcatccatc ctttcatctg tctatccata tcacaaacat gtattaaaca cctgctgtat -700 gctagacacc atcctgaagg tgcatttctt ccctaagtct tttttttgcc tgccggagag tacagtattc tcaattcaa ataa gaagtg gtgaataaga -600 gtgaagtgca aattggtgag gacacttaga caccgagtga ttacttctga caggtttcca ccactcagct aagtagcaag gtgaagactc cgaggttgag -500 ttgtaactca cagagoggga ałaccaatag gcagtgagaa aagaagttgc agtggcttca cgttatagca gatgectgtg tgtacacatg ggagcgaata -400 tggctttatg ctgttte ETS C/EBP

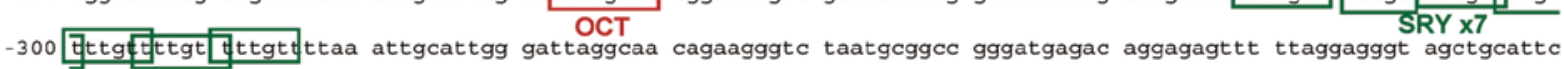
-200 taagtaaggg actctgcggg gggaaaagag gcgcaagcgt tgcaa gaagg gagtgcaggg ggttgagcag gcacctctac aggaaatgga tgctgtccag ETS
-100 gtgctggtgg gegccccagg getacgtggc gaagcagctc agccggtcca atpagagtgc gtccaggget cgggtttcge gatctttaag tgactgaggc

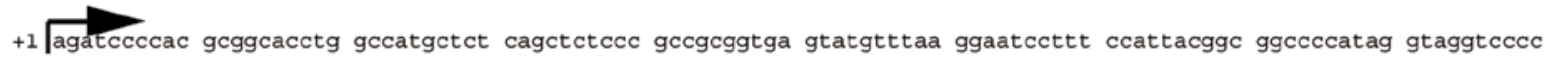
Exon1A +100 gtccgggaca gaggaagecg caacgggtcc cccegggeac cegggecttt ctcetgectc cegceacgtc cgagggtecg gecgcagege cggetgagec +200 cctccgcgge cggcagtggg aggegggetc tccgaaagcc gtcgcggtgg tcccagaagc cgggtcataa ataattcacg agccagggtc tggcgagcta

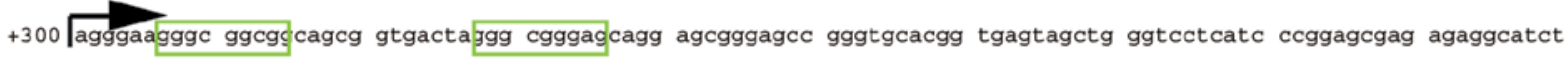
Exon1B GC box GC box

B
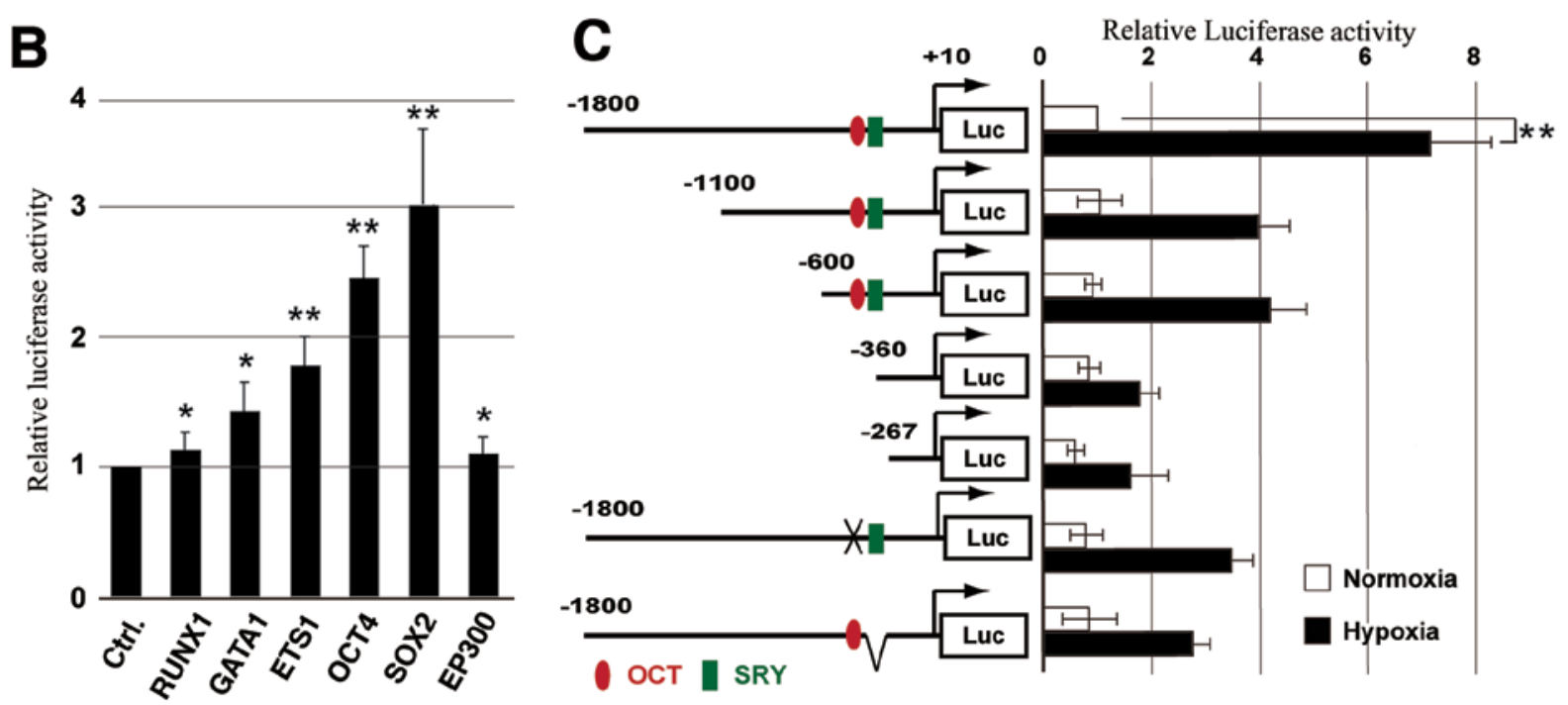

Figure 4. (A) Genomic nucleotide sequence of the human CD133P1 region. (B) Effects of ectopic expressions of transcription factor proteins. CD133P1 activities of $\mathrm{N} 417$ cells were transfected with control or expression vectors, and cultured for $24 \mathrm{~h}$ before culture under hypoxia. Asterisk indicates significantly different from the control (" $\mathrm{p}<0.05$ and $\left.{ }^{* *} \mathrm{p}<0.01\right)$. (B) Effects of deletion and mutation of OCT4- or SOX2-binding sites of CD133P1. Left panel, schematic representation of luciferase reporter construct containing the deletion and mutant sequences of the P1 region; right panel, luciferase activities of N417 cells transfected with a series of mutants. Asterisk indicates significantly different from normoxia ( ${ }^{* *} \mathrm{p}<0.01 \mathrm{vs}$ control).

\section{Discussion}

CD133 is considered to be a specific marker for CSCs, also referred to as tumor-initiating cells, in leukemia and solid tumors. In a recent report, CD133 was shown to be an important marker for non-small cell lung cancer (NSCLC) (34), but another report claimed that both $\mathrm{CD}^{-} 33^{-}$and $\mathrm{CD} 133^{+}$subpopulations in NSCLC and SCLC contain CSC (24). Thus CD133 has little 
A

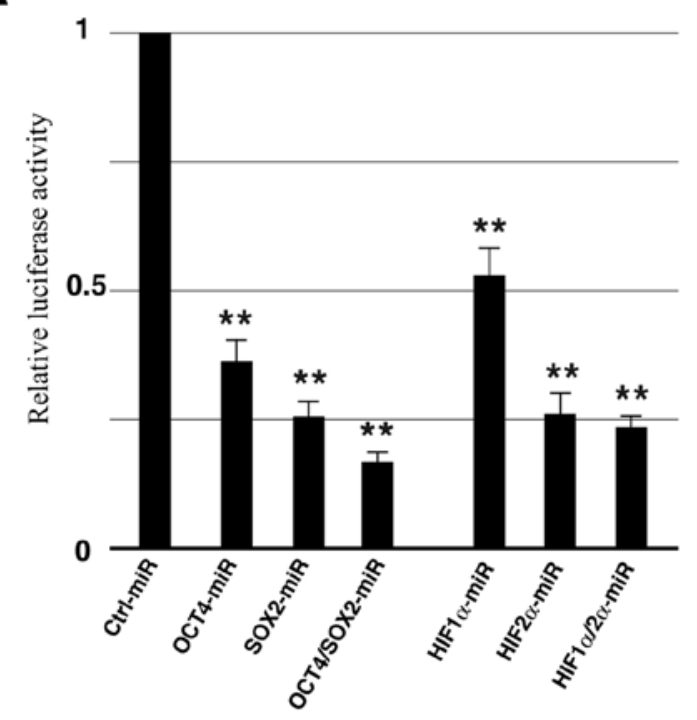

B

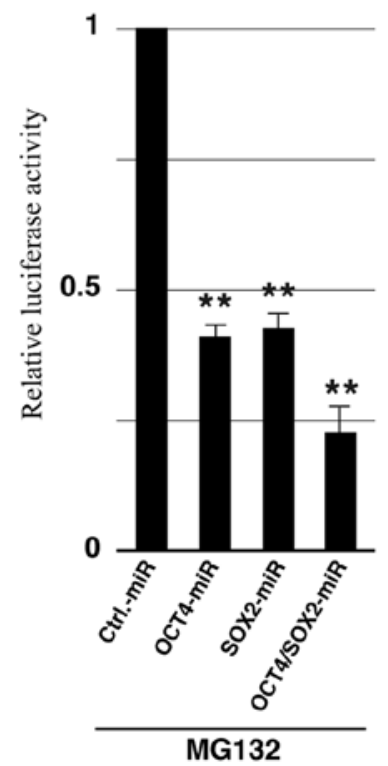

C

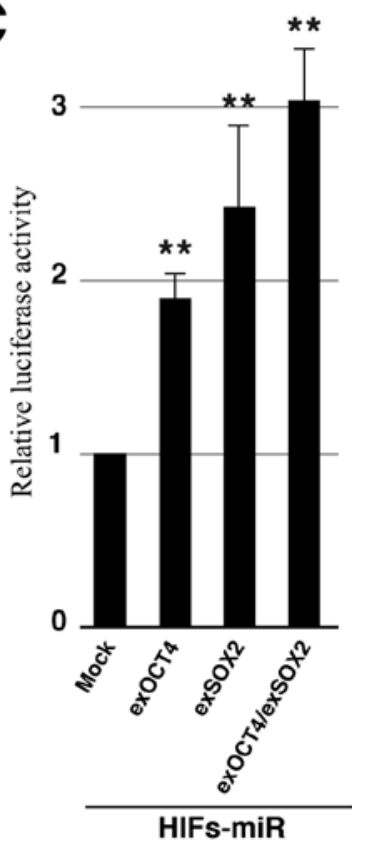

Figure 5. (A) Knockdown of OCT4, SOX2, HIF1 $\alpha$, and HIF $2 \alpha$ by miRNA expression vectors. CD133P1 activities of N417 cells transfected with control miRNA or target miRNA, and cultured for $24 \mathrm{~h}$ before initiation of hypoxic culture. (B) Knockdown of OCT4 and SOX2 by miRNA expression vectors. The CD133P1 activities of N417 cells were transfected with control miRNA or target miRNA expression vectors, and were treated with MG132. (C) Overexpression of OCT4 and SOX2 by expression vectors. CD133P1 activities of N417 cells were transfected with control or OCT4 or SOX2 expression vectors with HIFsmiRNA, and cultured for $24 \mathrm{~h}$ before initiation of hypoxic culture. All data are mean \pm SD of values from four independent experiments. Asterisk indicates significantly different from the control cells $\left({ }^{* *} \mathrm{p}<0.01\right.$ vs control-miR or mock cells).

value as a marker for CSC, and regulation of its expression requires further validation. In this study, we confirmed whether CD133 could be used as a specific marker for CSC in various lung cells. Given the difficulties of in vivo investigation, in vitro culture systems are an experimentally advantageous means for the identification and investigation of functions of the CD133 cell surface antigen. The tumor microenvironment normally exposes cells to hypoxia (35). In the present study, using FACS analysis, we have shown that $\mathrm{CD} 133^{+}$subpopulations increased when the cells were cultivated under hypoxic conditions of either 5 or $0.1 \%$, but were much reduced under hypoxic conditions of $20 \%$. Moreover, upregulation of CD133 expression by hypoxia varied between cell lines. N417 cells, derived from SCLC, showed greatly upregulated CD133 expression under hypoxic conditions. This sensitivity for hypoxia was correlated with poor prognosis. Our findings suggest that CD133 is regulated by oxygen levels and could be a useful marker for the detection of CSC, but that it would not be suitable for such a role in lung cancer.

The mechanisms of $C D 133$ expression have not yet been elucidated because $\mathrm{CD} 133^{+}$subpopulations are extremely rare in transcriptome analysis despite its expression being important as a stem-related biomarker. Moreover, the translational efficiency and stability of CD133 transcripts varied between 5' UTR sequences containing exon 1 (1A, 1B, 1C, 1D, or 1E). The 5' UTR region in CD133 is involved in the regulation of well-known proteins that regulate growth and differentiation of normal stem cells, and in the progression of specific types of cancers, such as leukemia and prostate cancer $(23,36,37)$. Therefore, the role of exon1 in CD133 expression needs to be determined. Some lung cell lines used in this study are suitable for further investigation of CD133 expression because this expression may be observed under the influence of oxygen levels. Fig. 2B illustrates that CD133P1 for exon 1A is used mainly for regulation of CD133 in N417 cells under hypoxic conditions. It has been shown that $\mathrm{P} 1$ and $\mathrm{P} 2$ could be used for CD133 expression in lung cancer cells (23), and this is corroborated by the findings of the present study.

Further investigations are needed to identify the underlying cis-regulatory elements on CD133P1; we found two previously undiscovered cis-elements, the POU- and SRY-binding sites (Fig. 4A). We have now confirmed the relationship between CD133 and its transcription factors in connection with the identified trans-acting transcription factors, OCT4 and SOX2. Our results, as shown in Figs. 4 and 5, also indicate that increased $C D 133$ expression in the hypoxia is regulated by OCT4 and SOX 2 rather than by HIF $1 \alpha / \mathrm{HIF} 2 \alpha$. Both OCT4 and SOX2 are essential for maintaining the undifferentiated state in embryonic stem (ES) cells. Hypoxia promotes the proliferation of ES and iPS cells more efficiently than normoxia and is thought to be required for the maintenance of their pluripotency $(33,38)$. Loss of function of OCT4 or SOX2 through miRNA inhibiton of tumorigenesis has been reported (39). CD133+ cells isolated by flow cytometry showed a higher tendency toward tumorigenesis than their CD133counterparts, but $\mathrm{CD}_{133^{+}}$was greatly reduced in the cell line transfected with both OCT4miR and SOX2miR in N417 (data not shown). Taken together, the significance of CD133 in CSC can be explained by the CD133-high subpopulation displaying higher OCT4 and SOX2 expression.

The regulatory mechanism of stem-related gene expression could help our understanding of tumor stemness and should be investigated further to improve the development of therapies against malignancies. However, the CD133- subpopulation also evidences tumorigenesis in some cancer cells $(22,24)$. Epigenetic modifications, such as DNA methylation and histone modification, have recently been reported to play important 

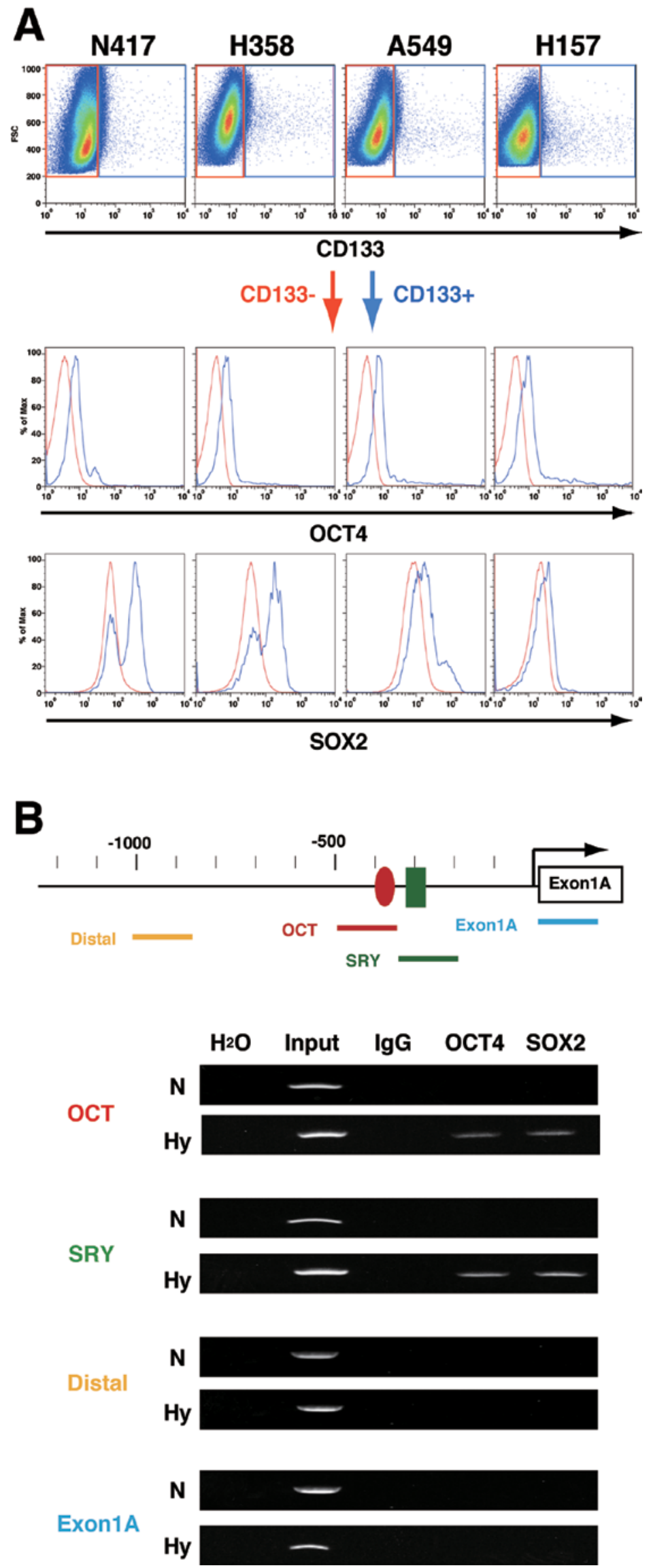

Figure 6. (A) FACS analysis of the OCT4 and SOX2 gates on CD133- (red) and CD133+ (blue) cells. (B) Binding of Oct4 and Sox 2 to the OCT (as represented by red) /SRY (as represented by green) elements, distal promoter region (as represented by yellow) and exon 1A region (as represented by blue). ChIP analyses were performed with anti-OCT4 antibody (OCT4) and anti-SOX2 antibody (SOX2), using normal rabbit IgG as the negative control (IgG). As the positive control, 1/100 amounts of input were used (input). Each sample for the PCR is indicated above the column. The genomic region with the OCT- and SRY-binding cis-elements, distal promoter, and exon 1A in CD133 was amplified with specific primers as indicated in Materials and methods. 
roles in the regulation of various genes $(19,40-42)$, which might be explained by a different cellular context of epigenetic regulation in lung cancer cell lines. Therefore, epigenetic modification may be the final determinant of CD133 expression and stem-like features. Further studies are needed to address the molecular mechanisms that epigenetically maintain the active state of CD133, particularly those involving DNA demethylases and/or histone acetyltransferases.

\section{Acknowledgments}

This work was mainly supported by a Grant-in-Aid for the Encouragement of Young Scientists (B) from the Ministry of Education, Science and Culture of Japan (no. 22790335 to M.S.). We wish to thank Dr D. Kitamura and Dr N. Hozumi, Tokyo University of Science, for their helpful suggestions.

\section{References}

1. Reya T, Morrison SJ, Clarke MF and Weissman IL: Stem cells, cancer, and cancer stem cells. Nature 414: 105-111, 2001.

2. Shackleton M, Quintana E, Fearon ER and Morrison SJ: Heterogeneity in cancer: cancer stem cells versus clonal evolution. Cell 138: 822-829, 2009.

3. Lapidot T, Sirard C, Vormoor J, et al: A cell initiating human acute myeloid leukaemia after transplantation into SCID mice. Nature 367: 645-648, 1994.

4. Dou J, Pan M, Wen P, et al: Isolation and identification of cancer stem-like cells from murine melanoma cell lines. Cell Mol Immunol 4: 467-472, 2007.

5. Singh SK, Clarke ID, Terasaki M, et al: Identification of a cancer stem cell in human brain tumors. Cancer Res 63: 5821-5828, 2003.

6. Al-Hajj M, Wicha MS, Benito-Hernandez A, Morrison SJ and Clarke MF: Prospective identification of tumorigenic breast cancer cells. Proc Natl Acad Sci USA 100: 3983-3988, 2003.

7. Monroe MM, Anderson EC, Clayburgh DR and Wong MH: Cancer stem cells in head and neck squamous cell carcinoma. J Oncol 2011: doi 762780, 2011.

8. Ricci-Vitiani L, Lombardi DG, Pilozzi E, et al: Identification and expansion of human colon-cancer-initiating cells. Nature 445 : 111-115, 2007.

9. Dick JE: Acute myeloid leukemia stem cells. Ann NY Acad Sci 1044: 1-5, 2005

10. O'Brien CA, Pollett A, Gallinger S and Dick JE: A human colon cancer cell capable of initiating tumour growth in immunodeficient mice. Nature 445: 106-110, 2007.

11. Weigmann A, Corbeil D, Hellwig A and Huttner WB: Prominin, a novel microvilli-specific polytopic membrane protein of the apical surface of epithelial cells, is targeted to plasmalemmal protrusions of non-epithelial cells. Proc Natl Acad Sci USA 94 12425-12430, 1997.

12. Miraglia S, Godfrey W, Yin AH, et al: A novel five-transmembrane hematopoietic stem cell antigen: isolation, characterization, and molecular cloning. Blood 90: 5013-5021, 1997.

13. Yin AH, Miraglia S, Zanjani ED, et al: AC133, a novel marker for human hematopoietic stem and progenitor cells. Blood 90 5002-5012, 1997.

14. Monzani E, Facchetti F, Galmozzi E, et al: Melanoma contains CD133 and ABCG2 positive cells with enhanced tumourigenic potential. Eur J Cancer 43: 935-946, 2007.

15. Tirino V, Desiderio V, d'Aquino R, et al: Detection and characterization of $\mathrm{CD}_{133}{ }^{+}$cancer stem cells in human solid tumours PLoS One 3: e3469, 2008.

16. Ma S, Chan KW, Hu L, et al: Identification and characterization of tumorigenic liver cancer stem/progenitor cells. Gastroenterology 132: 2542-2556, 2007.

17. Shmelkov SV, Meeus S, Moussazadeh N, et al: Cytokine preconditioning promotes codifferentiation of human fetal liver CD133 stem cells into angiomyogenic tissue. Circulation 111: 1175-1183, 2005.

18. Todaro M, Alea MP, Di Stefano AB, et al: Colon cancer stem cells dictate tumor growth and resist cell death by production of interleukin-4. Cell Stem Cell 1: 389-402, 2007.
19. Baba T, Convery PA, Matsumura N, et al: Epigenetic regulation of CD133 and tumorigenicity of CD133 ${ }^{+}$ovarian cancer cells. Oncogene 28: 209-218, 2009.

20. Bertolini G, Roz L, Perego P, et al: Highly tumorigenic lung cancer CD133+ cells display stem-like features and are spared by cisplatin treatment. Proc Natl Acad Sci USA 106: 16281-16286, 2009.

21. Beier D, Hau P, Proescholdt M, et al: CD133(+) and CD133(-) glioblastoma-derived cancer stem cells show differential growth characteristics and molecular profiles. Cancer Res 67: 4010-4015, 2007.

22. Shmelkov SV, Butler JM, Hooper AT, et al: CD133 expression is not restricted to stem cells, and both $\mathrm{CD} 33^{+}$and $\mathrm{CD} 133^{-}$metastatic colon cancer cells initiate tumors. J Clin Invest 118: 2111-2120, 2008.

23. Shmelkov SV, Jun L, St Clair R, et al: Alternative promoters regulate transcription of the gene that encodes stem cell surface protein AC133. Blood 103: 2055-2061, 2004.

24. Meng X, Li M, Wang X, Wang Y and Ma D: Both $\mathrm{CD}_{133^{+}}$and CD133- subpopulations of A549 and H446 cells contain cancerinitiating cells. Cancer Sci 100: 1040-1046, 2009.

25. Tirino V, Camerlingo R, Franco R, et al: The role of CD133 in the identification and characterisation of tumour-initiating cells in non-small-cell lung cancer. Eur J Cardiothorac Surg 36: 446-453, 2009.

26. Heddleston JM, Li Z, McLendon RE, Hjelmeland AB and Rich JN: The hypoxic microenvironment maintains glioblastoma stem cells and promotes reprogramming towards a cancer stem cell phenotype. Cell Cycle 8: 3274-3284, 2009.

27. McCord AM, Jamal M, Shankavaram UT, et al: Physiologic oxygen concentration enhances the stem-like properties of $\mathrm{CD}_{133^{+}}$ human glioblastoma cells in vitro. Mol Cancer Res 7: 489-497, 2009.

28. Mohyeldin A, Garzón-Muvdi T and Quiñones-Hinojosa A: Oxygen in stem cell biology: a critical component of the stem cell niche. Cell Stem Cell 7: 150-161, 2010.

29. Suzuki M, Yamada T, Kihara-Negishi F, et al: Site-specific DNA methylation by a complex of PU.1 and Dnmt3a/b. Oncogene 25: 2477-2488, 2006

30. Salnikov AV, Gladkich J, Moldenhauer G, Volm M, Mattern J and Herr I: CD133 is indicative for a resistance phenotype but does not represent a prognostic marker for survival of non-small cell lung cancer patients. Int J Cancer 126: 950-958, 2010.

31. Rankin EB and Giaccia AJ: The role of hypoxia-inducible factors in tumorigenesis. Cell Death Differ 15: 678-685, 2008.

32. Covello KL, Kehler J, Yu H, et al: HIF-2alpha regulates Oct-4: effects of hypoxia on stem cell function, embryonic development, and tumor growth. Genes Dev 20: 557-570, 2006.

33. Niwa H: Molecular mechanism to maintain stem cell renewal of ES cells. Cell Struct Funct 26: 137-148, 2001

34. Li F, Zeng $\mathrm{H}$ and Ying $\mathrm{K}$ : The combination of stem cell markers CD133 and ABCG2 predicts relapse in stage I non-small cell lung carcinomas. Med Oncol (In press).

35. Li Z, Bao S, Wu Q, et al: Hypoxia-inducible factors regulate tumorigenic capacity of glioma stem cells. Cancer Cell 15: 501-513, 2009.

36. Kemper K, Sprick MR, De Bree M, et al: The AC133 epitope, but not the CD133 protein, is lost upon cancer stem cell differentiation. Cancer Res 70: 719-729, 2010.

37. Tabu K, Kimura T, Sasai K, et al: Analysis of an alternative human CD133 promoter reveals the implication of Ras/ERK pathway in tumor stem-like hallmarks. Mol Cancer 9: 39, 2010.

38. Takahashi K and Yamanaka S: Induction of pluripotent stem cells from mouse embryonic and adult fibroblast cultures by defined factors. Cell 126: 663-676, 2006.

39. Chen YC, Hsu HS, Chen YW, et al: Oct-4 expression maintained cancer stem-like properties in lung cancer-derived CD133positive cells. PLoS One 3: e2637, 2008.

40. Tabu K, Sasai K, Kimura T, et al: Promoter hypomethylation regulates CD133 expression in human gliomas. Cell Res 18: 1037-1046, 2008.

41. Yi JM, Tsai HC, Glöckner SC, et al: Abnormal DNA methylation of CD133 in colorectal and glioblastoma tumors. Cancer Res 68: 8094-8103, 2008

42. You H, Ding W and Rountree CB: Epigenetic regulation of cancer stem cell marker CD133 by transforming growth factorbeta. Hepatology 51: 1635-1644, 2010. 